\title{
Construindo o Estado de Conhecimento sobre a contação de histórias na Extensão Universitária
}

\section{Editor}

Maria Inês Côrte Vitoria PUCRS, RS, Brasil

\section{Equipe Editorial}

Pricila Kohls dos Santos PUCRS, RS, Brasil Marcelo Oliveira da Silva PUCRS, RS, Brasil Carla Spagnolo PUCRS, RS, Brasil Rosa Maria Rigo PUCRS, RS, Brasil

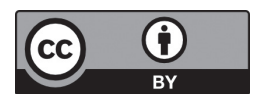

A matéria publicada neste periódico é licenciada sob forma de uma Licença Creative Commons - Atribuição 4.0 Internacional. http://creativecommons.org/licenses/by/4.0/
RESUMO: O presente artigo tem o objetivo de verificar a produção científica sobre a contação de histórias na extensão universitária, especificamente, com acadêmicos extensionista contadores de histórias, tendo o objetivo de esboçar o "estado de conhecimento" nesse campo de investigação. A seleção do material foi realizada através de leitura flutuante, no Banco de Teses da CAPES - Coordenação de Aperfeiçoamento de Pessoal de Nível Superior, das dissertações e teses defendidas em 2011 e 2012, único período provisoriamente disponível. A metodologia adotada para a produção deste artigo foi a leitura flutuante, bibliografia anotada e, posteriormente, a análise de dados. O artigo apresenta um breve panorama sobre a importância da contação de história, da extensão universitária, o estado de conhecimento e as considerações finais, que buscam evidenciar as conclusões da pesquisadora. Observa-se que a produção científica na temática contação de histórias, embora em número cada vez maior, ainda é bastante tímida, se relacionada às estudadas neste artigo.

Palavras-chave: Estado de conhecimento. Contação de histórias. Extensão Universitária. Projeto de extensão. Formação de leitores. Banco de Teses/CAPES.

\begin{abstract}
This work is intended check the scientific literature on storytelling in university extension specifically for academic storytelling, with the aim of delineating the "state knowledge "in this field of research. The selection of material was performed by floating reading in the database Thesis CAPES - Coordination of Improvement of Higher Education Personnel /Brazil, of dissertations and theses produced in the years 2011 and 2012. The methodology is floating reading, annotated bibliography and data analysis. The article presents a brief description of the importance of storytelling, university extension, the state of knowledge and the final considerations, trying to highlight the conclusions of the research. It is noted that scientific studies on storytelling, although increasing numbers, is still very timid in relation to the terms studied in this article.
\end{abstract}

Keyworks: State of knowledge. Storytelling. University Extension. Extension Project. Training readership. Bank Thesis/ CAPES.

\footnotetext{
a Licenciada em Letras, especialista em Língua Espanhola, Mestranda do Programa de Pós-Graduação em Educação da PUCRS/Agência Financiadora: CAPES. E-mail: <carla.cassel@hotmail.com>.
} 
contação de histórias está inserida em projetos de extensão universitária da Universidade Federal do Rio Grande

do Sul, doravante, UFRGS, denominados Libros Viajeros, Arte de Ler, Brincando com a Leitura na Pequena Casa da Criança, realizados e já finalizados na Faculdade de Biblioteconomia e Comunicação; e projeto Conta Mais, iniciado na Coordenadoria de Educação Básica e Profissional e, atualmente, desenvolvido no Museu Universitário da UFRGS.

O atual Conta Mais, assim como os anteriores projetos, tem o objetivo de promover a leitura e a literatura infantil e juvenil na Creche, Brinquedoteca da UFRGS e em escolas públicas, nas quais a biblioteca não funciona ou não realiza atividades de promoção da leitura e literatura. A metodologia é através dos serviços de caixa-estante e contação de histórias ${ }^{1}$, complementada, após, com atividades lúdicas.

No Museu Universitário da UFRGS, o projeto Conta Mais, também, oferece contações de histórias no local, gratuitamente, para o público visitante das exposições. Posso salientar a importância da contação de histórias em um espaço, fora do contexto escolar, que procura ratificar a literatura como um meio de aproximar o educando às artes, à história do homem, às conquistas, à cultura geral, ao gosto pela leitura e ao simples prazer de escutar uma boa história. A literatura nos transforma e nós, contadores de histórias, transformamos um "pouquinho" as pessoas.

O contato com a realidade das escolas, através desses projetos de extensão universitária, acima citados, permitiu constatar alguns problemas existentes no contexto escolar. As escolas têm suas bibliotecas fechadas ou abertas em horário reduzido, por um responsável, geralmente um professor "recolocado" que, em muitos casos, não realiza atividade de promoção da leitura. Quando fechadas, o professor é o responsável em levar seus alunos na Biblioteca e depois organizar o que "desarrumaram", dificultando seu trabalho. Os livros ficam à disposição dos professores e alunos, mas não há alguém para dinamizar a utilização dos mesmos. Muitos professores, às vezes, não se permitem contar uma história ou ler um conto, não encontram ou não conhecem o prazer, valor e encantamento na literatura $\mathrm{e}$ na contação de histórias. Não há um programa mais intenso e específico para a prática leitora.

Entretanto, muitas mudanças ocorreram com o desenvolvimento dos projetos nas escolas. Alguns exemplos de transformação podem ser citados: escolas que a biblioteca estava fechada, professores se mobilizaram e criaram plantões para utilizá-la melhor; professores que ficavam em biblioteca começaram a buscar cursos de contação de histórias e livros de suporte teórico para promoção da leitura; realização de feiras de livros; criação de grupos de alunos contadores de histórias para os mais novos, a participação de pais e avós para contar histórias; a valorização do idoso e da família através de histórias; a designação de um tempo determinado para a "parada da leitura",

\footnotetext{
1 Por contação de histórias entende-se pelo momento reservado para os alunos desfrutarem da história apresentada por contadores, utilizando
} diferentes técnicas e recursos, tais como: avental, teatro de fantoches, flanelógrafo, quadro de pregas, álbum seriado e outros. 
onde todas as turmas param o que estão fazendo e leem livros; a confecção de livros; passeio à Feira de Livros de Porto Alegre, etc.

Quanto aos ouvintes, nesse caso, os alunos, com idades entre 3 a 17 anos, de creches ou escolas, que escutaram as histórias, mostraram através do brilho de seus olhos, da boca entreaberta e vacilante, na dúvida, inconsciente, de fechá-la ou deixá-la como está, nos gestos de sustos ou enternecimentos, demostraram sua participação atenta e seu envolvimento durante a narração das histórias, demonstraram um certo vínculo com o contador e uma disponibilidade inenarrável de escutar histórias. A mudança de comportamento desses alunos, a atenção dispensada durante as histórias, seu entusiasmo e alegria ao receber o contador chamaram a atenção dos relatórios realizados pelos alunos bolsistas do projeto.

Nas reuniões e avaliações que são feitas após o término de atendimento do projeto às escolas, nos relatos dos professores em relação às atitudes de seus alunos são destacados a mudança de comportamento, mais atenção nas aulas, mais disposição para aprender, maior procura de livros na biblioteca da escola, mais cobrança para contar histórias para eles, melhoria do vocabulário oral e escrito, mais leituras. E em relação a si próprios, declaram que passam a ler mais, com mais gosto e variedade, procurando inovar suas aulas com mais leitura e literatura. Esse olhar dos professores veio migrar para um prazer da leitura, prazer em contar histórias e notável gosto pela leitura, tanto do professor, quanto de seu aluno, um prazer em expressar o que descobriu em uma história ou em narrar o que mais lhe agradou. Seus depoimentos assumem um começo ou uma descoberta de "gostar de ler".

Por outro lado, o acadêmico bolsista lê muitas histórias para descobrir qual história ele se identifica mais, aprende as técnicas da narração e, muitas vezes, confecciona os recursos de contação de histórias, como fantoches, bonecos, desenhos. Toma consciência da importância de uma boa contação, lê suportes teóricos sobre promoção da leitura, literatura infantil e contação de histórias. O projeto serve como laboratório para o bolsista, pois este tem o contato direto com a realidade escolar, com o público infantil, com o falar em público, com a reflexão e decisão de qual história contar, como contar, o que explorar, de qual atividade lúdica para contextualizar a história após a contação da mesma. Esse acadêmico pode permanecer no projeto, se o quiser, por dois anos, tempo suficiente para aprender e desenvolver seu gosto pela leitura e literatura, habilidades comunicativas, criatividade, crítica construtiva e ampliar seus poderes de observação e percepção.

Não há pesquisa realizada sobre os referidos projetos, entretanto algumas inquietações despertaram meu interesse: os alunos bolsistas que trabalharam no projeto no passado, que hoje, professores, contam histórias para seus alunos? Com recursos específicos, técnicas que aprenderam naquela época e atividades pertinentes à promoção da leitura e do assunto que querem abordar, sem esquecer o prazer e a ludicidade que estão na literatura? Qual é a contribuição para a formação acadêmica e profissional do universitário ter passado por projetos de extensão de contação de histórias 
para aquele, também, que não era de cursos de licenciatura? As contações de histórias realizadas pelo aluno bolsista influenciaram em relação a sua vida acadêmica e profissional? De que maneira? O que ficou na memória desse aluno em relação ao projeto?

Surgiu, então, o interesse na busca de como vem sendo tratada a temática contação de histórias na extensão universitária nas produções científicas, mais precisamente com contadores de histórias acadêmicos extensionistas.

Diante do exposto, este artigo tem como objetivo mapear e discutir a produção acadêmica sobre contação de histórias no âmbito da extensão universitária, que para isso, utilizei como principal referencial de busca o Banco de Teses da CAPES - Coordenação de Aperfeiçoamento de Pessoal de Nível Superior, investigando os estudos apresentados em 2011 e 2012.

\section{A contação de histórias}

Os contos orais sempre fizeram parte da vida das pessoas, na Antiguidade se reuniam para ouvir os eventos do dia, histórias de viagens, as façanhas dos aventureiros. Tudo para compartilhar experiências e emoções, para passar o tempo, se divertir, "matar" a curiosidade, viajar com a imaginação através das histórias ou até mesmo conhecer um pouco mais do mundo e de lugares desconhecidos. As pessoas precisavam de respostas para perguntas que elas não sabiam responder e imaginavam histórias que foram contadas de geração em geração.

Llosa (1987, p. 92) afirma que "contar histórias pode ser mais do que apenas diversão. Algo primordial, algo que depende da existência de um povo. Um povo sem história é um povo sem memória, não é um povo." A história vai mostrar quem eram essas pessoas e/ou por que elas são assim, sua origem, sua memória, sua cultura, costumes, sua própria identidade e existência. Cada indivíduo tem uma história, e cada história individual está cheia de várias pequenas histórias, desde a concepção até a morte, o que chamamos de histórias pessoais comuns. Seguindo essas histórias, individual e coletivamente, criamos as histórias das pessoas, que indicam um tempo vivido um tempo decorrido de vida e morte, alegrias e tristezas, sucessos e frustrações.

Segundo Sosa (1982, p. 114), as histórias transmitiram através de imagem, fatos da realidade dos homens primitivos, não só por prazer e diversão, mas para difundir o conhecimento e lições práticas de vida, nas quais se mostrava o mundo como o homem supunha ter se originado. A literatura é um fenômeno criativo que representa o homem, mostra a vida e o mundo através da palavra, considerada uma arte em sua estética e apresentação. A literatura é caracterizada pela sua capacidade de simbolização, a função poética da linguagem supera a função referencial, estabelece a polissemia, ou seja, a ambiguidade do discurso literário. Neste sentido, podemos dizer que o discurso literário é mais rico quanto maior a diversidade de leituras permitidas. 
Conforme Bettelheim (2007, p. 9), na audição de histórias, pessoas de todas as idades, mas principalmente as crianças e pré-adolescentes, conseguem o distanciamento necessário dos problemas para interpretá-los no contexto ressignificado do texto que escutam e com o auxílio da ação daqueles personagens para resolver as diversas situações que enfrentam. Entendem que seus problemas reais são iguais ou parecidos aos das histórias, se identificando com a história, com um personagem e se sentindo mais perto dela com os seus problemas, conflitos e experiências de vida, enquanto procuram ou descobrem que existem soluções, existem maneiras para diminuir as dificuldades, bem como o personagem conseguiu fazer.

A literatura infantil tem um papel importante, decisivo e fundamental no universo infantil, pois é através da fantasia, imaginação, emoção e diversão que a criança apreende a realidade, dando sentido ao seu mundo. As histórias estimulam a imaginação, a atenção, a curiosidade e ajudam a criança a criar soluções, entendendo o conflito, lendo o mundo e compreendendo outras culturas, outros povos.

Abramovich afirma:

É ouvindo histórias que se pode sentir (também) emoções importantes, como tristeza, raiva, a irritação, o bem-estar, o medo, a alegria, insegurança, e tantas outras mais, e viver profundamente tudo o que a narrativas provocam em que as ouve - com toda a amplitude, significância e verdade que cada uma delas fez (ou não) brotar... Pois é ouvir, sentir e enxergar com os olhos do imaginário. (ABRAMOVICH, 1997, p. 17)

A criança se identifica com os personagens, começa a experimentar o jogo na ficção e é projetada no tecido da narrativa, para fazer a catarse. A história lida ou contada desempenha um papel catalisador de interesse e prazer, e o ouvinte vivencia, temporariamente, angústias e alegrias identificando os sentimentos que estão presentes, sem qualquer risco. Se as crianças estão mobilizadas na narrativa, o mundo está organizado, correspondendo aos seus interesses e desejos, e, é claro, é significativo para elas.

\section{A Extensão Universitária}

Na Lei n ${ }^{\circ}$ 9.394, de 20 de dezembro de 1996, a Lei de Diretrizes e Bases da Educação Nacional estabelece as diretrizes e bases da educação nacional, no cap. IV, art. $43^{\circ}$, como uma das finalidades da educação superior, o parágrafo VII, promover a extensão, aberta à participação da população, visando à difusão das conquistas e benefícios resultantes da criação cultural e da pesquisa científica e tecnológica geradas na instituição. Estabelece, também, no parágrafo anterior, a finalidade de estimular o conhecimento dos problemas do mundo presente, em 
particular os nacionais e regionais, prestar serviços especializados à comunidade e estabelecer com esta uma relação de reciprocidade.

Segundo Mosorini (2006) a Extensão Universitária é considerada uma das três funções centrais da universidade, ao lado do ensino e da pesquisa.

A extensão universitária é o processo educativo, cultural e científico que articula o ensino e a pesquisa de forma indissociável e viabiliza a relação transformadora entre universidade e sociedade. É uma via de mão dupla, com trânsito assegurado à comunidade acadêmica, que encontrará na sociedade a oportunidade da elaboração da práxis de um conhecimento acadêmico. (GARRAFA, 1989, p. 109)

No Plano Nacional de Extensão Universitária, edição atualizada (Brasil, 2000-2001), Fórum de Pró-Reitores de Extensão das Universidades Públicas Brasileiras e SESu/MEC, ainda consta:

No retorno à Universidade, docentes e discentes trarão um aprendizado que, submetido à reflexão teórica, será acrescido àquele conhecimento. Esse fluxo, que estabelece a troca de saberes sistematizados, acadêmico e popular, terá como consequências a produção do conhecimento resultante do confronto com a realidade brasileira e regional, a democratização do conhecimento acadêmico e a participação efetiva da comunidade na atuação da Universidade. Além de instrumentalizadora deste processo dialético de teoria/prática, a Extensão é um trabalho interdisciplinar que favorece a visão integrada do social.

Os contadores, após a contação de história apresentada na escola pública, voltam à Universidade, cheios de novidades e observações, detalhes que, às vezes, imperceptíveis, no momento da história, mas que depois, vêm à tona, pela reflexão de suas atitudes, suas posturas e direcionamentos.

\section{Construindo o Estado de Conhecimento}

Com o objetivo de mapear e discutir a produção acadêmica sobre contação de histórias no âmbito da extensão universitária, utilizei como principal referencial de busca o Banco de Teses da CAPES - Coordenação de Aperfeiçoamento de Pessoal de Nível Superior, onde constam as dissertações e teses defendidas em 2011 e 2012.

A Tabela 1, a seguir, oferece uma visão das temáticas procuradas e o resultado encontrado, bem como sua porcentagem. 
Tabela 1 - Apresentação das temáticas estudadas

\begin{tabular}{|c|c|c|c|c|c|}
\hline \multirow{2}{*}{ Palavras-chave } & \multicolumn{2}{|c|}{ Dissertações } & \multicolumn{2}{|c|}{ Teses } & \multirow{2}{*}{ Total de Estudos } \\
\hline & № & $\%$ & № & $\%$ & \\
\hline Contação de Histórias & 28 & 87,5 & 4 & 12,5 & 32 \\
\hline Área de Conhecimento/Educação & 13 & 87 & 3 & 13 & 16 \\
\hline Palavra-chaves/Contação de Histórias & 1 & 100 & 0 & 0 & 1 \\
\hline Extensão Universitária & 0 & 0 & 0 & 0 & 0 \\
\hline Sujeito de Pesquisa - Contador de História & 2 & 100 & 0 & 0 & 2 \\
\hline Extensão Universitária & 164 & 76 & 53 & 24 & 217 \\
\hline Área de Conhecimento/Educação & 57 & 74 & 20 & 26 & 77 \\
\hline Palavra-chave/Extensão Universitária & 8 & 67 & 4 & 33 & 12 \\
\hline Palavra-chave/Contação de Histórias & 0 & 0 & 0 & 0 & 0 \\
\hline Projeto de Extensão & 273 & 80 & 65 & 20 & 338 \\
\hline Área de Conhecimento/Educação & 26 & 72 & 10 & 28 & 36 \\
\hline Palavra-chave/Projeto de Extensão & 1 & 100 & 0 & 0 & 1 \\
\hline Sujeito de Pesquisa - Aluno Universitário & 1 & 100 & 0 & 0 & 1 \\
\hline Formação de Leitor & 269 & 86 & 46 & 14 & 315 \\
\hline Área de Conhecimento/Educação & 73 & 85 & 13 & 15 & 86 \\
\hline Resumo/Contação de Histórias & 3 & 75 & 1 & 25 & 4 \\
\hline
\end{tabular}

Na busca geral com a temática "contação de histórias" foram encontrados 32 estudos, sendo 16 na área da Educação: treze dissertações e três teses. Os demais são na área de Letras, 07 dissertações e uma tese; em Psicologia, 03 dissertações e 1 tese; em Artes, 02 dissertações e na área de Enfermagem, 01 dissertação. A porcentagem é apresentada no Gráfico 1: 
Gráfico 1 - Apresentação da temática contação de histórias

por áreas de conhecimento

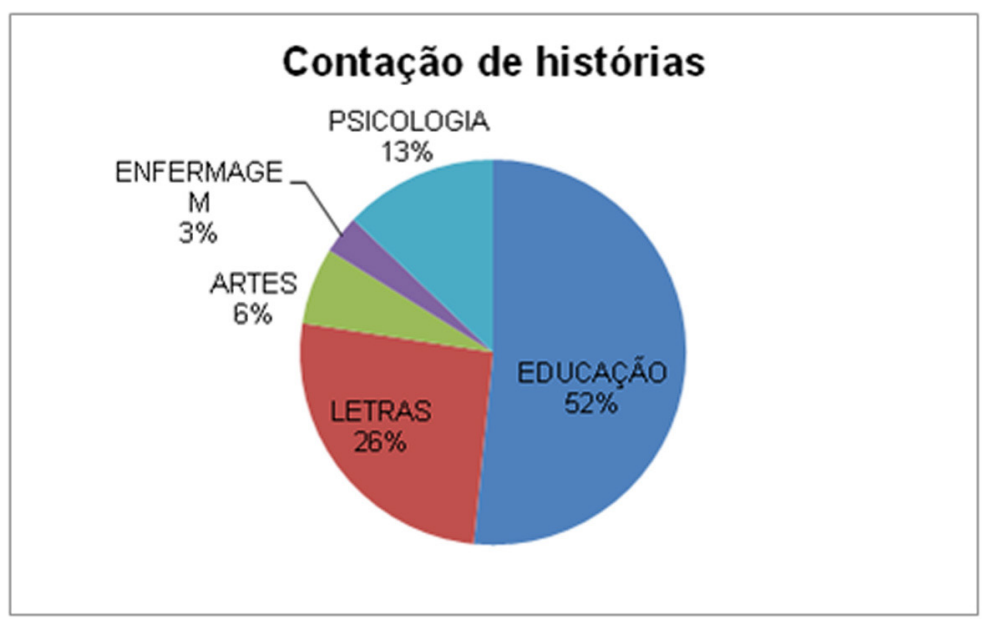

Na busca avançada, com a palavra-chave "contação de histórias", apareceram somente 04 trabalhos, então constatei que muitas pesquisas não foram computadas no resultado da busca, mesmo sendo a temática mencionada no campo palavra-chave das pesquisas.

Realizei, então, dentre os 16 estudos na área de Educação, uma busca pormenorizada, individual, investigando os sujeitos de pesquisa. Notei que 14 estudos sobre contação de histórias têm diversos enfoques, tendo como sujeito de pesquisa, alunos do Ensino Fundamental, bebês de berçários, jovens leitores, autônomos, crianças hospitalizadas, etc.

Encontrei apenas 02 estudos na área de Educação, os quais seus sujeitos pesquisados são contadores de histórias, porém nenhum desses trata de acadêmicos contadores de histórias, enfoque deste levantamento.

O primeiro estudo denominado $O$ que narram os contadores de histórias: memórias, histórias e práticas, de autoria de Simone Ribeiro Barros André, dissertação defendida em 2012, analisa a complexidade da contação de histórias considerando-a como prática social, cultural e educativa, centrando a atenção nos saberes, ações e processos de reflexão de três contadores de histórias que atuam em distintos espaços, escolas, bibliotecas e centros culturais do Rio de Janeiro. 
A segunda dissertação, intitulada "Corporeidade e Humanescência: cenários ludopoiéticos na vida de Professores Contadores de História", de Maria das Dores da S.T. Câmara, defendida também em 2012, procura ressaltar a afirmação da corporeidade de professoras contadoras de histórias, de forma que participem de uma dinâmica criativa de si mesmas e do contexto em que vivem, tomando como ponto de partida a necessidade de mudança de paisagem da educação.

Analisando pesquisas nas outras áreas de conhecimento, posso salientar a dissertação na área das Artes Cênicas, a qual a pesquisadora fez parte de um projeto de extensão, como contadora de história e acadêmica da UFRGS. Essa dissertação chamada Quem conta um conto: o amor como encontro na contação de histórias, de Luciene Rivoire, defendida em 2012, visa refletir sobre as relações de amor na contação de histórias através do relato das experiências do grupo Quem conta um conto - contadores de histórias, de alunos extensionistas e da trupe Quem conta um conto, grupo de contadores de histórias.

Também busquei pela palavra contadores de histórias, os quais foram encontrados 17 estudos com essa temática. Muitos desses eram os mesmos que, já citados acima, apareceram com a temática contação de história. Saliento o trabalho de Mestrado Acadêmico em História, de Aldanei Menegaz de Andrade, Quem conta um conto, aumenta um ponto: contadores de histórias no Distrito Federal, cujo objetivo é identificar e evidenciar a presença de contadores de histórias e suas práticas no Distrito Federal.

Cabe citar, também o estudo A arte de contar histórias e a formação de novos leitores em múltiplos suportes, de Jucelma Terezinha Neves Schneid, dissertação defendida em 2011, Mestrado em Letras da Universidade de Passo Fundo, na qual seus sujeitos de pesquisa são três contadores de histórias. O estudo investiga sobre a arte de contar histórias e sua importância como prática formadora de leitores, em relação aos demais suportes e linguagens, dos tradicionais aos digitais, esboçando um perfil dos contadores de histórias da atualidade.

Acreditando que a contação de histórias contribui para a formação de leitores, procurei no Banco da Capes, na busca geral a temática formação de leitor, no qual foram encontrados 315 trabalhos. Dentre esses, 86 estudos na área da Educação. Encontrando somente um estudo com essa temática formação de leitor e contação de história nas palavras-chave, resolvi buscar esta última (contação de história), também, no resumo desses 86 estudos, cujo resultado foram apenas 04 estudos encontrados.

Dentre esses, ressalto Contação de histórias: um caminho para a formação de leitores?, dissertação de Ana Claudia Ramos, defendida em 2011, com o objetivo de verificar efeitos das narrativas orais, ou seja, dos possíveis decorrentes da contação de histórias para a formação de alunos-leitores, e descobrir se e como o desempenho do professor durante a contação de histórias influencia o interesse do aluno em ler outros livros.

Através dessa investigação, Ramos (2011) declara: 
[...] foi possível demonstrar a contação de história como mais uma estratégia fundamental na formação do leitor garantindo-se, com isso, o enriquecimento do processo educacional sob uma perspectiva que valoriza a constituição de sujeitos críticos e reflexivos. Isso porque as narrativas orais, especialmente as que têm por suporte a leitura de textos literários, como foi o caso deste estudo, condensam em si caminhos plurissignificativos para a leitura e compreensão de si e do mundo. (RAMOS, Ana C., 2011)

Como a contação de histórias em projetos de extensão tem como sujeito alunos bolsistas foi pesquisada a temática "extensão universitária". Nos anos de 2011 e 2012, na busca geral foram encontrados 217 trabalhos, sendo 164 dissertações e 53 teses. Os estudos encontrados apresentam-se na proporção apresentada no Gráfico 2, por área de conhecimento:

Gráfico 2 - Apresentação da Extensão Universitária por área de conhecimento

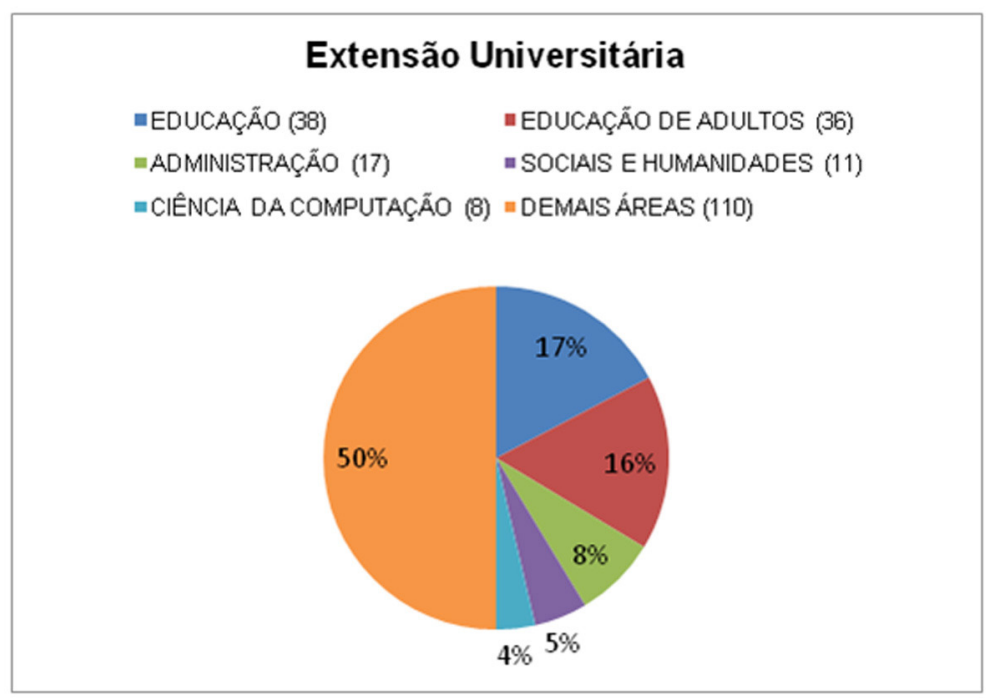


Na busca avançada, na área da Educação, 77 estudos distribuídos em 57 dissertações e 20 teses, sendo 38 em Educação, 36 em Educação de Adultos e 3 em Educação Física (busca termo generalizado Educação). E analisando o gráfico acima, se juntarmos as áreas de educação com a educação de adultos ficaria em 33\% na área da educação.

Para filtrar mais a busca, investiguei a temática Extensão Universitária nas palavras-chave, que foram encontradas 12 estudos: 04 teses e 08 dissertações, que representam um percentual de $66,7 \%$ de dissertações. Porém nenhum estudo foi encontrado com as palavras-chave contação de história juntamente com a Extensão Universitária.

Na categoria Projeto de Extensão, 338 estudos constavam no Banco de dados da Capes, sendo 273 dissertações e 65 teses. Na área de conhecimento da Educação são 36, sendo 34 dissertações e 2 teses. Foi localizada uma dissertação que trata sobre a contribuição de projetos de extensão, tendo como sujeitos de pesquisa, estudantes universitários, porém não são contadores de histórias.

Tal estudo denomina-se "A contribuição da extensão na formação do estudante universitário", de autoria de Aurélio Rodrigues da Silva, defendido em 2011, na Universidade Católica de Brasília, que investiga a experiência de aprendizagem de estudantes que estiveram envolvidos em projetos de extensão de uma Universidade particular do Distrito Federal.

\section{Considerações finais}

A partir dos dados analisados, nota-se que o número de dissertações é expressivamente maior do que o número de teses nas temáticas estudadas. Ressalto a temática contação de histórias, em que 87,5\% dos estudos são dissertações e 12,5\% são teses de Doutorado. Dos 32 estudos sobre contação de história, 52\% estão na área de Educação, 26\% nas Letras, 13\% em Psicologia, 6\% em Artes e 3\% em Enfermagem. Acredito que esses dados estão dentro de um resultado praticamente previsto, o qual a contação está mais presente nas áreas de Educação e depois nas Letras, áreas diretamente ligadas à leitura, literatura e formação de leitores.

A temática contação de histórias foi observada em 14 estudos no ano de 2011 e em 18 no ano de 2012, representando um aumento de $28,5 \%$ no número de pesquisas em relação ao ano anterior.

Em relação aos 217 estudos com a temática extensão universitária, 107 foram defendidos em 2011, sendo 82 dissertações e 25 teses; e 110 defendidos em 2012, dentre os quais, 82 dissertações e 28 teses. É interessante ressaltar o número igual de dissertações nos dois anos estudados e um aumento de $12 \%$ no número de teses de um ano para o outro. 
Observa-se que a produção de conhecimento na temática contação de histórias, embora em número cada vez maior, ainda é bastante tímida, se relacionada às temáticas estudadas neste artigo: extensão universitária, projeto de extensão e formação de leitor.

A maioria das pesquisas encontradas sobre formação de leitor, contação de histórias, seus sujeitos de pesquisa são os ouvintes, professores, alunos do Ensino Fundamental, bebês de berçários, jovens leitores, autônomos, crianças hospitalizadas, etc. Faz-se necessária a escuta dos narradores e contadores de histórias, a contribuição das narrações de histórias para esses sujeitos.

A respeito da contação de história como atividade, pode-se considerar uma prática incipiente dentro das ações investigadas no viés da extensão universitária.

Acredito que este artigo possa contribuir para futuros estudos sobre a contação de histórias e servir de instrumento para valorizar a produção científica sobre a arte de narrar ou contar histórias para a vida escolar, acadêmica e para a vida pessoal. O quão importante é fazer um levantamento de pesquisas existentes sobre determinados assuntos, para avaliar a validade da pesquisa e para não torná-la repetitiva e desnecessária.

Tendo em vista à boa qualidade das pesquisas que constam no Banco de Teses da Capes, acredito que poderiam ser mais ou melhor divulgadas na classe de professores de todas as áreas, talvez, nos cursos de formação inicial ou continuada. Os professores teriam uma noção da produção científica de seu interesse e poderiam seguir ou utilizar diversas estratégias expostas e/ou aprovadas nesses estudos, podendo servir de estímulo para esse professor começar uma pesquisa há muito desejada e não realizada.

\section{Referências}

ABRAMOVICH, Fanny. Literatura infantil: gostosuras e bobices. São Paulo: Scipione, 1997.

ANDRADE, Aldanei Menegaz de. Quem conta um conto, aumenta um ponto: contadores de histórias no Distrito Federal (1991 a 2011). 2012. 144 f. Dissertação (Mestrado em História) - Instituto de Ciências Humanas, Universidade de Brasília, Brasília, 2012. Disponível em: <http://repositorio.unb.br/handle/10482/11641>. Acesso em: 24 abr. 2014.

ANDRÉ, Simone Ribeiro Barros. O que narram os contadores de histórias: memórias, histórias e práticas. 2012. 295f. (Mestrado Acadêmico em Educação) - Faculdade de Formação de Professores de São Gonçalo, Universidade do Estado do Rio de Janeiro, Rio de Janeiro, 2012. Disponível em: <http://ppgedu.org/wp-content/uploads/2014/02/Dissertação-Simone-André.pdf>. Acesso em: 27 abr. 2014.

BETTELHEIM, Bruno. A psicanálise dos contos de fadas. 21. ed. São Paulo: Paz e Terra, 2007.

BRASIL. Ministério da Educação. Lei n 9.394, de 20 de dezembro de 1996 - Lei de Diretrizes e Bases da Educação Nacional. Brasília, DF, MEC, 1996. Disponível em: <http://portal.mec.gov.br/arquivos/pdf/ldb.pdf>. Acesso em: 19 maio 2014. 
CAMARA, Maria das Dores da Silva Timoteo da. Corporeidade e humanescência: cenários ludopoiéticos na vida de professores contadores de história. 2012. 159f. Dissertação (Mestrado Acadêmico em Educação) - Universidade Federal do Rio Grande do Norte, Natal, 2012.

COORDENAÇÃO DE APERFEIÇOAMENTO DE PESSOAL DE NÍVEL SUPERIOR. CAPES. Banco de Teses e Dissertações. Disponível em: <http://www.capes.gov.br/servicos/banco-de-teses>. Acesso em: 21 mar. 2014.

LLOSA, Mario Vargas. El hablador. Santiago: Siex Barral, 1987.

MOROSINI, Marília Costa (Org.). Enciclopédia de Pedagogia Universitária. v. 2. Brasília, DF: Inep/MEC, 2006.

RAMOS, Ana Claudia. Contação de histórias: um caminho para a formação de leitores? 2011. 133p. Dissertação (Mestrado em Educação) - Centro de Educação, Comunicação e Artes, Universidade Estadual de Londrina, Londrina, 2011. Disponível em: <http:// www.uel.br/pos/mestredu/images/stories/downloads/dissertacoes/2011/2011_-_RAMOS_Ana_Claudia.pdf>. Acesso em: 21 mar. 2014.

RIVOIRE, Luciene. Quem conta um conto: o amor como encontro na contação de histórias. 2012. Dissertação (Mestrado Acadêmico em Artes Cênicas) - Instituto de Artes, Universidade Federal do Rio Grande do Sul, Porto Alegre, 2012. Disponível em: <http://www. lume.ufrgs.br/bitstream/handle/10183/61123/000864831.pdf? sequence=1>. Acesso em: 27 abr. 2014.

SCHNEID, Jucelma Terezinha Neves. A arte de contar histórias e a formação de novos leitores em múltiplos suportes. 2011. 96f. Dissertação (Mestrado em Letras) - Instituto de Filosofia e Ciências Humanas, Universidade de Passo Fundo, Passo Fundo, 2011. Disponível em: <http://www.lume.ufrgs.br/bitstream/handle/10183/61123/000864831.pdf?sequence=1>. Acesso em: 24 abr. 2014.

SOSA, Jesualdo. La literatura infantil. Ensayo sobre ética, estética y psicopedagogía de la literatura infantil. 7. ed. Buenos Aires: Losada, 1982.

UNIVERSIDADE FEDERAL DO RIO GRANDE DO SUL. Pró-Reitoria de Extensão. PROREXT. Disponível em: <http://www. ufrgs.br/prorext/prorext-1>. Acesso em: 20 mar. 2014.

\section{Endereço para correspondência:}

Carla Cassel Silva

Rua Machado de Assis, 855/1202

90620-260 Porto Alegre, RS, Brasil

E-mail: <carla.cassel@hotmail.com>

Recebido em: jun./2014

Aceito em: ago./2014 